\title{
Success rate and safety of catheter ablation in preexcitation syndrome: A comparison between adult and pediatric patients
}

\author{
Radosław Pietrzak ${ }^{1}$, Magda Franke ${ }^{2}$, Monika Gawałko ${ }^{3}$, Piotr Lodziński , \\ Paweł Balsam ${ }^{3}$, Marcin Grabowski ${ }^{3}$, Bożena Werner ${ }^{1}$ \\ ${ }^{1}$ Department of Pediatric Cardiology and General Pediatrics, Medical University of Warsaw, Poland \\ ${ }^{2}$ Student Scientific Circle, Department of Pediatric Cardiology and General Pediatrics, \\ Medical University of Warsaw, Poland \\ ${ }^{3} 1^{\text {st }}$ Chair and Department of Cardiology, Medical University of Warsaw, Poland
}

\begin{abstract}
Background: In contrast to adults, in whom cardiac rhythm disorders are mainly conditioned by coronary artery disease, in children, arrhythmias are most often associated with inherited heart disorders. Catheter ablation (CA) has an important role in the management of cardiac arrhythmias, in adults and children. The aim of the study was to assess and compare the efficacy and safety of $C A$ in children and adults with preexcitation syndrome.

Methods: The study population comprised 43 adults and 43 children diagnosed with a Wolff-Parkinson-White syndrome (WPW). The mean age of the study population was $41 \pm 15$ years for adults and $14 \pm 2.5$ years for children. In all patients, an electrophysiological study and CA were performed. Analysis with respect to the procedure duration, fluoroscopy exposure time, location of accessory pathways $(A P)$, immediate success rate and complications were performed.

Results: Electrophysiological study revealed the most frequent presence of left-sided AP (56\% in children and $70 \%$ in adults). The mean procedure duration was $96 \pm 36$ min and $106 \pm 51$ min in children and adults, respectively $(p=N S)$. The mean fluoroscopy duration was $8.5 \pm 4.3$ min and $5.9 \pm 5.8$ min in children and adults, respectively $p<0.05$. The CA procedure was successful in 40 out of 43 (93\%) adults and in 36 out of $43(83.7 \%)$ children ( $p=N S)$. In $2(4 \%)$ children minor complications occurred.

Conclusions: Ablation in children and adults are equally effective with respect to short-term clinical observation. (Cardiol J 2022; 29, 1: 88-92)

Key words: catheter ablation, preexcitation syndrome, accessory pathways, arrhythmia, children, adults
\end{abstract}

\section{Introduction}

Catheter ablation (CA) procedure has become a crucial way of treatment for heart rhythm disturbances both in an adult and pediatric populations. Since it was introduced in children at the beginning of the 90 s', it has completely changed the approach to a vast majority of arrhythmias, including supraventricular tachycardias due to preexcitation syndrome [1]. Preexcitation syndrome is the most common indication to $\mathrm{CA}$ in the pediatric population. However, in many countries, this way of treatment still presents a big challenge due to a lack of centres specialized in CA in children.

Address for correspondence: Radoslaw Pietrzak, MD, PhD, Department of Pediatric Cardiology and General Pediatrics, Medical University of Warsaw, ul. Żwirki i Wigury 63A, 02-091 Warszawa, Poland, tel: +48 2231795 88, tel/fax: + 482231795 89, e-mail: radoslaw.pietrzak@wum.edu.pl

Received: 6.10.2019 Accepted: 17.02.2020 Early publication date: 11.03.2020

This article is available in open access under Creative Common Attribution-Non-Commercial-No Derivatives 4.0 International (CC BY-NC-ND 4.0) license, allowing to download articles and share them with others as long as they credit the authors and the publisher, but without permission to change them in any way or use them commercially. 
Moreover, many physicians still consider CA as a risky procedure in children. Due to this fact they try to postpone CA, limiting sport participation until they are successfully treated. It may have some deleterious consequences considering both general health and social life for children.

Atrial fibrillation (AF) is the most common arrhythmia in adults however, there is still a considerable group of patients with preexcitation syndrome. AF is considered a major risk factor for sudden cardiac death in adult patients with preexcitation syndrome (Wolff-Parkinson-White syndrome [WPW]). For these reasons, CA has to be considered in patients with WPW before the risk of AF increases.

The aim of the study was to assess and compare the efficacy and safety of CA in children and adults suffering from WPW.

\section{Methods}

The retrospective study was performed. The study group comprised 43 consecutive paediatric patients with an average age of $14 \pm 2.5$ years and 43 consecutive adult patients with an average age of $41 \pm 15$ years (Table 1 ). Patients with WPW were referred to electrophysiological study (EPS) and CA between 2016 and 2017. Diagnosis of WPW and the accessory pathways (AP) location were based on 12-lead standard electrocardiogram (ECG) using the Lucas Boersma algorithm before the procedure and confirmed during EPS [2]. In all patients, a morphologically normal heart was confirmed by echocardiography using the Philips iE33 system (Philips Medical Systems, Andover, MA, USA).

\section{EPS and ablation strategy}

All adults underwent EPS and CA according to the same scheduled conduct routinely followed in the site as follows. All antiarrhythmic agents were withdrawn at least five half-lives prior to the procedure. Vascular access was gained via femoral veins. Two diagnostic catheters were introduced for the EPS and were placed in the right ventricle and coronary sinus. Programmed atrial and ventricular stimulation was performed to induce atrioventricular re-entrant tachycardia (AVRT) and to measure the effective refractory period (ERP) of the AP, which was the longest A1-A2 interval without preexcitation. In patients with left-sided pathways, a transseptal puncture was performed to access the left atrium (LA). After the transseptal puncture, patients were heparinised when LA access was needed (target activated clotting time 300-400 s).
Table 1. Demographic data.

\begin{tabular}{lcc}
\hline Characteristics & Adults & Pediatric patients \\
\hline Number of patients & 43 & 43 \\
Female/male & $18 / 25$ & $13 / 30$ \\
Mean age [years] & $41 \pm 15$ & $14 \pm 2.5$ \\
Weight [kg] & $80 \pm 21$ & $32 \pm 4.5$ \\
\hline
\end{tabular}

The ablation catheters were navigated under fluoroscopic and electroanatomic system guidance (Carto 3, Johnson and Johnson, USA). Catheter ablation followed the diagnostic EPS. Programmed atrial and ventricular stimulation was performed to confirm the diagnosis of WPW, induce AVRT and prove the presence of an additional pathway, as well as to localize the exact location of the accessory pathways, as described in the literature [3]. On three-dimensional (3D) map, directly before ablation, the bundle signal was marked using an ablation catheter.

The following settings were used while delivering radiofrequency energy: irrigated tip ablation - power control mode (temperature limit $48^{\circ} \mathrm{C}$, power limit of $30 \mathrm{~W}$; Navistar ThermoCool, Biosense Webster, Diamond Bar, CA, USA). The CA was defined as a successful when 15 min after the procedure, provided no signs of arrhythmia were documented.

\section{Statistical analysis}

Results are presented as mean \pm standard deviation (SD) and percentages. Demographic, EP, CA procedure and complications were analyzed. The Spearman test was used to calculate correlations. The Fisher exact test was used in the analysis of contingency tables. Significance was taken as being $\mathrm{p}<5 \%$. All tests were performed using Statistica 13.2 software.

\section{Bioethics committee}

The study was registered in the University Bioethics Committee. Written, informed consent was obtained prior to the procedure from all patients and in the case of children - from the parents and from patients above 15 years of age.

\section{Results}

\section{Electrophysiological study}

In $24(56 \%)$ of the children and $30(70 \%)$ of the adults, AP was diagnosed on the left side. Left free wall was the most common location, 16 (37\%) and 


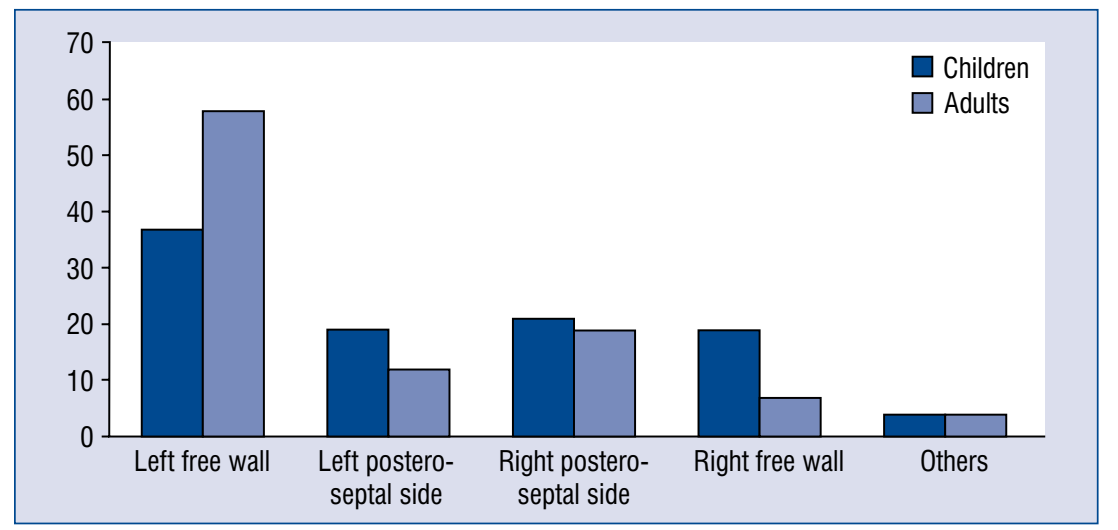

Figure 1. Locations of accessory pathways in children and adults.

Table 2. Procedure data.

\begin{tabular}{lccc}
\hline Parameter & Adults $(\mathbf{n}=\mathbf{4 3})$ & Pediatric patients $(\mathbf{n}=43)$ & P \\
\hline Time of procedure $[\mathrm{min}]$ & $96 \pm 36$ & $106 \pm 51$ & NS \\
Fluoroscopy time $[\mathrm{min}]$ & $5.9 \pm 5.8$ & $8.5 \pm 4.3$ & $<0.05$ \\
Fluoroscopy dose $\left[\mu \mathrm{GY} / \mathrm{cm}^{2}\right]$ & $12 \pm 13$ & $17 \pm 11$ & NS \\
Transseptal puncture & $31(72.1 \%)$ & $23(53.5 \%)$ & $\mathrm{NS}$ \\
Complications & $0(0.0 \%)$ & $2(4 \%)$ & - \\
Success rate & $40(93 \%)$ & $36(83.7 \%)$ & NS \\
\hline
\end{tabular}

$25(58 \%)$ in children and in adults, respectively. The AP was located on the left posteroseptal side in $8(19 \%)$ children and $5(12 \%)$ in adults. Transseptal puncture was conducted in all cases when AP was located on the left side. The most frequent location on the right side was the right posteroseptal AP $-9(21 \%)$ in children and $8(19 \%)$ in adults. Right side free wall AP was diagnosed in $8(19 \%)$ children and $3(7 \%)$ in adults. Two children and two adults were diagnosed with a right anteroseptal location of AP (Fig. 1). The ERP was assessed in both groups. In children, the mean ERP at rest was $275 \pm 86.5 \mathrm{~ms}$ and in adults, the mean ERP was $250 \pm 56.8 \mathrm{~ms}(\mathrm{p}=\mathrm{NS})$.

\section{Catheter ablation}

The mean procedure duration was shorter in children $(96 \pm 36 \mathrm{~min})$ than in adults $(106 \pm 51$ $\mathrm{min})$ but this difference was not statistically significant $(\mathrm{p}=\mathrm{NS})$. The mean fluoroscopy duration in children was statistically significantly longer than in adults and was $8.3 \pm 4.3$ min vs. $5.9 \pm 5.8$ min, respectively $(\mathrm{p}<0.05)$. The success rate was satisfactory in both groups. In the pediatric population, 15 min after the procedure, arrhythmia was not documented in 36 out of 43 children (84\%) whereas in adults it was 40 out of 43 patients (93\%) and this difference was not statistically significant ( $\mathrm{p}=\mathrm{NS}$; Table 2).

Two pediatric patients had minor complications - one had a first-degree atrioventricular block and the second had a pseudoaneurysm in the location of the catheter. No complications in adults were noted.

\section{Discussion}

For a long time now, catheter ablation has been a leading procedure in the treatment of WPW in the adult population. In accordance with its high success and safety rate, it has become to play an important role in the treatment of children $[4,5]$. In this study, an experience in the ablation of cardiac arrhythmias in children and adolescents is presented and these data are compared with the data derived from the adult center. The procedures were performed by the same team, at the same time in both populations, which makes the study unique. This allowed us to rule out any trial limitations resulting from an altered approach to the procedure due to individual experience and customs of the team. 
In the present study, most of the accessory pathways were located on the left side (53 out of 86 patients), which is in agreement with $\mathrm{Di}$ Biase et al. study [6]. They found that the AP was located on the left lateral wall in 50-60\%, on the posteroseptal wall in 25-30\% and within the right free wall space in $10-21 \%$. As it is well described in current publications, success is higher for leftsided pathways than for any other location. This fact may be explained by better catheter stability and a simpler anatomy of the LA, which facilitates detailed mapping along the mitral valve annulus $[7,8]$. The difference in immediate success rate in children and adults in the current study was not statistically significant and came to $83.7 \%$ and $93 \%$, respectively. These data are similar to the data given in the literature separately for both populations. According to data in the literature, the immediate success rate in pediatric population ranges from between $87.5 \%$ and $97 \%[3,4,7,9,10]$. In Lee et al. study [11] CA was successful in 93\% of adults. The Pediatric Radiofrequency Ablation Registry reported an early success rate at the level of $94.4 \%$, for ablation of accessory pathways in all locations [12, 13].

According to the published data, pharmacological treatment of supraventricular tachycardia (SVT) in the pediatric population appeared effective in about $64 \%$ of all the cases, depending on the type of arrhythmia and medication. As it was mentioned above, the CA procedure has a significantly higher success rate than pharmacological treatment [13-16]. In terms of effectiveness, these results emphasize the superiority of ablation over pharmacology.

At a pediatric age, ablation is usually more difficult than in adult patients due to the small body size, different electrical properties of the cardiac conduction system, as well as slightly different relations of anatomical structures of children's hearts. These factors not only make placing the electrodes properly inside the heart more difficult but also increase the possibility of damaging significant heart structures. They also have some impact on judgment of the diagnostic pacing manoeuvre during EPS. Moreover, they explain longer fluoroscopy time during the procedures in the paediatric population. Due to these facts, the use of $3 \mathrm{D}$ mapping is a useful tool to consider, especially in the pediatric population. 3D mapping additionally shortens the fluoroscopy time and makes all procedures safer, considering deleterious effect of an $\mathrm{X}$-ray to developing systems and organs in children because of the cumulative risk of radiation. In the documented Center, mean fluoroscopy time was similar to that reported in the literature. According to the Multicentre Pediatric and Congenital EP Quality Initiative (MAP-IT) registry, fluoroscopy time in pediatric ablation has improved over the last 25 years from $47.6 \pm 40 \mathrm{~min}$ to $7.0 \pm 9.2 \mathrm{~min}$ $(\mathrm{p}<0.001)$ [9], whereas in the current Center it was $8.5 \pm 4.3$ and $5.9 \pm 5.8 \mathrm{~min}$ in children and adults, respectively. Therefore, the present study is in accordance with trials when considering trends in fluoroscopy time reduction.

According to the present data, $9 \%$ of pediatric patients encompassed minor complications, the most serious of which was a transient first-degree atrioventricular block. According to Lee et al. study [11], it is a common complication. Compared to the present results, in Melo et al. [17] the study procedure-related complications were observed among $12 \%$ of children with clinically documented SVT who underwent CA and in $11.7 \%$ of pediatric patients in the study conducted by Hafez et al. [5].

To conclude, CA has changed the approach to the management of cardiac arrhythmias due to its better effectiveness than pharmacological treatment. It is also more cost-effective than long-term pharmaceutical treatment [18].

\section{Limitations of the study}

The study population was relatively small as it encompassed only patients with WPW.

\section{Conclusions}

Ablation in children and adults are equally effective with respect to short-term clinical observation.

\section{Conflict of interest: None declared}

\section{References}

1. Klitzner TS, Wetzel GT, Saxon LA, et al. Radiofrequency ablation. A new era in the treatment of pediatric arrhythmias. Am J Dis Child. 1993; 147(7): 769-771, doi: 10.1001/archpedi.1993.02160310071021, indexed in Pubmed: 8322749.

2. Boersma L, García-Moran E, Mont L, et al. Accessory pathway localization by QRS polarity in children with Wolff-ParkinsonWhite syndrome. J Cardiovasc Electrophysiol. 2002; 13(12): 1222-1226, doi: 10.1046/j.1540-8167.2002.01222.x, indexed in Pubmed: 12521337.

3. Ceresnak SR, Dubin AM, Kim JJ, et al. Success rates in pediatric WPW ablation are improved with 3-dimensional mapping systems compared with fluoroscopy alone: a multicenter study. J Cardiovasc Electrophysiol. 2015; 26(4): 412-416, doi: 10.1111/ jce.12623, indexed in Pubmed: 25600208. 
4. Pruszkowska-Skrzep P, Pluta S, Lenarczyk A, et al. A comparison of the clinical course of preexcitation syndrome in children and adolescents and in adults Cardiol J. 2007; 14(4): 384-390.

5. Hafez MM, Abu-Elkheir MM, Shokier M, et al. Radiofrequency catheter ablation in children with supraventricular tachycardias: intermediate term follow up results. Clin Med Insights Cardiol. 2012; 6: 7-16, doi: 10.4137/CMC.S8578, indexed in Pubmed: 22259261 .

6. Di Biase L, Walsh EP. (2018, August). Epidemiology, clinical manifestations, and diagnosis of the Wolff-Parkinson-White syndrome. Retrieved from. http://www.uptodate.com.

7. Knight BP. Anatomy, pathophysiology, and localization of accessory pathways in the preexcitation syndrome. Retrieved from. http://www.uptodate.com.

8. Van Hare GF, Javitz H, Carmelli D, et al. Pediatric Electrophysiology Society. Prospective assessment after pediatric cardiac ablation: demographics, medical profiles, and initial outcomes. J Cardiovasc Electrophysiol. 2004; 15(7): 759-770, doi: 10.1046/j.1540-8167.2004.03645.x, indexed in Pubmed: 15250858 .

9. Dubin AM, Jorgensen NW, Radbill AE, et al. What have we learned in the last 20 years? A comparison of a modern era pediatric and congenital catheter ablation registry to previous pediatric ablation registries. Heart Rhythm. 2019; 16(1): 57-63, doi: 10.1016/j.hrthm.2018.08.013, indexed in Pubmed: 30118886.

10. Soongswang J, Bhuripanyo K, Raungratanaamporn O, et al. Radiofrequency catheter ablation in pediatrics: experience at Siriraj Hospital. J Med Assoc Thai. 2000; 83(11): 1340-1347, indexed in Pubmed: 11215864.

11. Lee PC, Hwang B, Chen SA, et al. Electrophysiologic characteristics and radiofrequency catheter ablation in children with Wolff-Parkinson-White syndrome. Pacing Clin Electrophysiol. 2006; 29(5): 490-495, doi: 10.1111/j.1540-8159.2006.00381.x, indexed in Pubmed: 16689844.
12. Van Hare GF, Javitz H, Carmelli D, et al. Prospective assessment after pediatric cardiac ablation: demographics, medical profiles, and initial outcomes. J Cardiovasc Electrophysiol. 2004; 15(7): 759-770, doi: 10.1046/j.1540-8167.2004.03645.x, indexed in Pubmed: 15250858 .

13. Kugler JD, Danford DA, Houston KA, et al. Pediatric radiofrequency catheter ablation registry success, fluoroscopy time, and complication rate for supraventricular tachycardia: comparison of early and recent eras. J Cardiovasc Electrophysiol. 2002; 13(4): 336-341, doi: 10.1046/j.1540-8167.2002.00336.x, indexed in Pubmed: 12033349 .

14. Läer S, Elshoff JP, Meibohm B, et al. Development of a safe and effective pediatric dosing regimen for sotalol based on population pharmacokinetics and pharmacodynamics in children with supraventricular tachycardia. J Am Coll Cardiol. 2005; 46(7): 1322-1330, doi: 10.1016/j.jacc.2005.06.061, indexed in Pubmed: 16198851.

15. Núñez F, Ruiz-Granell R, Martínez-Costa C, et al. Safety and efficacy of flecainide in the treatment of symptomatic children with Wolff-Parkinson-White syndrome. Pediatr Cardiol. 2010; 31(8): 1162-1165, doi: 10.1007/s00246-010-9772-z, indexed in Pubmed: 20717658.

16. Perry JC, Garson A. Flecainide acetate for treatment of tachyarrhythmias in children: review of world literature on efficacy, safety, and dosing. Am Heart J. 1992; 124(6): 1614-1621, doi: 10.1016/0002-8703(92)90081-6, indexed in Pubmed: 1462922.

17. Melo S, Scanavacca M, Pisani C, et al. Ablação com RF de arritmia na infância: registro observacional em 125 crianças. Arquivos Brasileiros de Cardiologia. 2012; 98(6): 514-518, doi: 10.1590/ s0066-782x2012005000042.

18. Cheng CH, Sanders GD, Hlatky MA, et al. Cost-effectiveness of radiofrequency ablation for supraventricular tachycardia. Ann Intern Med. 2000; 133(11): 864-876, doi: 10.7326/0003-4819133-11-200012050-00010, indexed in Pubmed: 11103056. 